Article

\title{
Caffeine Inhibits Acetylcholinesterase, But Not Butyrylcholinesterase
}

\section{Miroslav Pohanka ${ }^{1, *}$ and Petr Dobes ${ }^{2}$}

1 Faculty of Military Health Sciences, University of Defense, Trebesska 1575, 50001 Hradec Kralove, Czech Republic

2 Regional Centre for Applied Molecular Oncology, Masaryk Memorial Cancer Institute, Zluty Kopec 7, 65653 Brno, Czech Republic; E-Mail: pietroli@seznam.cz

* Author to whom correspondence should be addressed; E-Mail: miroslav.pohanka@gmail.com; Tel./Fax: +420-973-253-091.

Received: 4 April 2013; in revised form: 29 April 2013 / Accepted: 30 April 2013 /

Published: 8 May 2013

\begin{abstract}
Caffeine is an alkaloid with a stimulant effect in the body. It can interfere in transmissions based on acetylcholine, epinephrine, norepinephrine, serotonin, dopamine and glutamate. Clinical studies indicate that it can be involved in the slowing of Alzheimer disease pathology and some other effects. The effects are not well understood. In the present work, we focused on the question whether caffeine can inhibit acetylcholinesterase (AChE) and/or, butyrylcholinesterase (BChE), the two enzymes participating in cholinergic neurotransmission. A standard Ellman test with human AChE and BChE was done for altering concentrations of caffeine. The test was supported by an in silico examination as well. Donepezil and tacrine were used as standards. In compliance with Dixon's plot, caffeine was proved to be a non-competitive inhibitor of AChE and BChE. However, inhibition of $\mathrm{BChE}$ was quite weak, as the inhibition constant, $\mathrm{K}_{\mathrm{i}}$, was $13.9 \pm 7.4 \mathrm{~mol} / \mathrm{L}$. Inhibition of $\mathrm{AChE}$ was more relevant, as $\mathrm{K}_{\mathrm{i}}$ was found to be $175 \pm 9 \mu \mathrm{mol} / \mathrm{L}$. The predicted free energy of binding was $-6.7 \mathrm{kcal} / \mathrm{mol}$. The proposed binding orientation of caffeine can interact with Trp86, and it can be stabilize by Tyr337 in comparison to the smaller Ala328 in the case of human BChE; thus, it can explain the lower binding affinity of caffeine for $\mathrm{BChE}$ with reference to AChE. The biological relevance of the findings is discussed.
\end{abstract}


Keywords: acetylcholinesterase; butyrylcholinesterase; caffeine; Alzheimer disease; myasthenia gravis; acetylcholine; inhibition; coffee; alkaloid; chocolate

\section{Introduction}

In the body, two structurally close esterases with different functions can be found. While acetylcholinesterase (AChE) (EC 3.1.1.7.) is involved in the termination of neurotransmission, the role of butyrylcholinesterase (BChE) (EC 3.1.1.8.) is not understood. Acetylcholine is a low molecular weight neurotransmitter presented in both the central and peripheral nervous system. It is responsible for signal transmission from nerves to terminal glands and muscles. In the body, nicotinic (nAChR) and muscarinic acetylcholine receptors (mAChR) are present. The receptors are expressed in most tissues, and they can be found on leukocytes, endothelial cells, nerves and others [1-3]. AChE is an enzyme converting acetylcholine into choline and acetate. Neurotransmission is stopped by the AChE effect [4,5].

$\mathrm{AChE}$ is a target for many drugs and toxins. Organophosphorus pesticides, carbamate pesticides and nerve agents are examples of toxic compounds inhibiting $\mathrm{AChE} \mathrm{[6,7].} \mathrm{Huperzine} \mathrm{and} \mathrm{its}$ derivative, ZT-1, donepezil, galantamine and rivastigmine can be mentioned as drugs for Alzheimer disease inhibiting AChE [8-10]. Compared to drugs for Alzheimer disease penetrating through the blood-brain barrier, drugs for myasthenia gravis, such as pyridostigmine and neostigmine, inhibit $\mathrm{AChE}$ in peripheral nerves $[11,12]$. BChE is not sensitive to all of the AChE inhibitors. Irreversible and pseudo-irreversible inhibitors represented by the aforementioned pesticides, nerve agents, rivastigmine, pyridostigmine and neostigmine have nearly equal affinity to AChE and BChE [4]. $\mathrm{BChE}$ does not have a simply defined role in the body. Drugs interacting with the cholinergic system are not focused on $\mathrm{BChE}$ for that reason. The enzyme can be found in many tissues, and the expression is not privileged to the closeness of nerves, like in the AChE case. Significant production of BChE can be found in the liver, from where the enzyme is released into the blood system, and it circulates in plasma in a level of $5 \mathrm{mg} / \mathrm{mL}[13,14]$.

Caffeine (shown in Figure 1) is a well-known plant alkaloid found in coffee beans from Coffea arabica, C. canephora and some other Coffea plants. It is known to be in tea leaves of Camellia sinensis as well. People typically accept caffeine from coffee, tea, energy and cola drinks. Besides the presence in the drinks, caffeine is used as a stimulant supplement and medical stimulant in combination with other compounds $[15,16]$. The caffeine's stimulant effect is based on nonselective adenosine receptor antagonism [17]. However, the adenosine receptors are not the only targets of caffeine. It can meet acetylcholine-, epinephrine-, norepinephrine-, serotonin-, dopamine- and glutamate-mediated neurotransmission [18-22]. Phosphodiesterases inhibition and promotion of calcium release from intracellular stores can be attributed to caffeine, as well [23,24]. The implication in the acetylcholine-based neurotransmission is plausibly verified [25]. Caffeine regulatory potency in the body is an object of extensive research, and some of the caffeine related pathways probably remain unrevealed [26]. The present paper describes the search on caffeine potency to modulate the activity of cholinesterases, a crucial part of the cholinergic system. We try to answer the question whether 
caffeine can act via acetylcholine receptors only or whether it can be involved in the regulation of the neurotransmitter, acetylcholine, via cholinesterases.

Figure 1. Structure of caffeine.

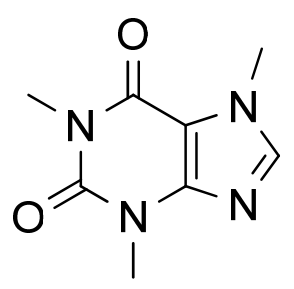

\section{Results and Discussion}

Donepezil and tacrine were assayed as standard non-competitive inhibitors of AChE. The inhibitors have no significant affinity to $\mathrm{BChE}$. The inhibition constant, $\mathrm{K}_{\mathrm{i}}$, for donepezil was assayed to be $23.8 \mathrm{nmol} / \mathrm{L}$. Tacrine was scored to have an inhibition constant, $\mathrm{K}_{\mathrm{i}}$, equal to $189 \mathrm{nmol} / \mathrm{L}$. The experimental values are in compliance with the literature search, where $\mathrm{K}_{\mathrm{i}}$ equal to $12.5 \mathrm{nmol} / \mathrm{L}$ for donepezil and $105 \mathrm{nmol} / \mathrm{L}$ can be found for $\mathrm{AChE}$ from rat erythrocytes [27]. The differences between the values subtracted from the literature and the results reported here can be caused by the fact that human AChE was used in our experiment. Small structural alteration between AChE from different organisms can be responsible for the result difference.

An assay of caffeine using human AChE is shown in Figure 2. Non-competitive mechanism of inhibition can be easily assumed from the plot. Experimental values for the lines and calculated $\mathrm{K}_{\mathrm{i}}$ values for each line are depicted in Table 1 . The correlation coefficients, $\mathrm{R}$, are quite high, which confirms the precision of the assay. The $\mathrm{K}_{\mathrm{i}}$ value for caffeine and human AChE was calculated to be (mean \pm standard deviation) $175 \pm 9 \mu \mathrm{mol} / \mathrm{L}$. Comparing to AChE, BChE had only minimal sensitivity to inhibition by caffeine. Experimental data for caffeine and human BChE are depicted in Table 2. As the affinity of caffeine to $\mathrm{BChE}$ was low, the fitted lines had low slopes, and correlation coefficients were not good for the reason. The $\mathrm{K}_{\mathrm{i}}$ value for $\mathrm{BChE}$ was nearly 80,000 times higher than for AChE: $13.9 \pm 7.4 \mathrm{~mol} / \mathrm{L}$.

The crystal structure of human AChE with donepezil was considered for docking [28], because it would obtain a more accurate basis for the explanation of the structural feature than the previously available ones. Firstly, donepezil was re-docked to the same binding orientation, as in the crystal structure (the predicted free energy of binding was $-12.2 \mathrm{kcal} / \mathrm{mol}$ ). The phenyl ring was stacked on Trp86 with a $\pi-\pi$ interaction. Additionally, galantamine was docked in a similar orientation, as in the crystal structure (pdb code 4ey6 [28]; the predicted free energy of binding is $-10.1 \mathrm{kcal} / \mathrm{mol}$ ). It occupied a whole internal cavity with the active site. Finally, the molecule of caffeine was docked (predicted free energy of binding, $-6.7 \mathrm{kcal} / \mathrm{mol}$ ). The predicted binding orientation of caffeine is stacked toward Trp86 (3.6 $\AA$ ) with $\pi-\pi$ interaction similar to the phenyl cycle of donepezil. Furthermore, there can exist two hydrogen bonds between caffeine and Ser125 (3.1 $\AA$ ) and a weaker hydrogen bond with Tyr133 (3.6 $\AA$ ). The binding orientation of caffeine can be stabilized by Tyr337 (3.7 $\AA$ ) in comparison to human BChE, where it is in the position situated on Ala328, which is not able to extend to the predicted caffeine binding orientation. This can explain the weaker binding activity for 
$\mathrm{BChE}$ in comparison to $\mathrm{AChE}$. The docked orientation of caffeine in the AChE structure is depicted in Figure 3. BChE has very low binding affinity; thus, it was not modeled by docking, as the program is not suitable for such weak interactions.

Figure 2. Dixon plot for human acetylcholinesterase (AChE). The concentration of the substrate is indicated beside each line. The data are extrapolated to cross the X-axis. Error bars reflect a standard deviation for $n=4$.

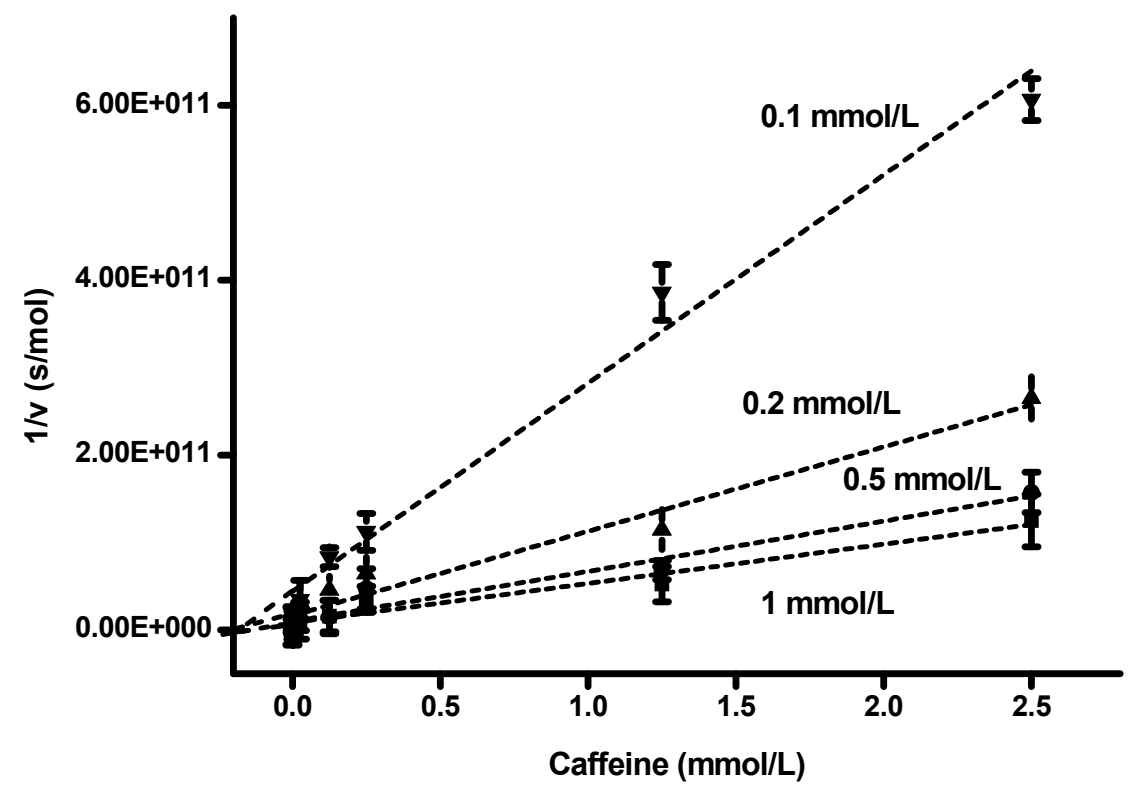

Table 1. Search on inhibitory mechanism using human AChE.

\begin{tabular}{ccccc}
\hline Substrate $(\mathbf{m m o l} / \mathbf{L})$ & Slope $\left(\mathbf{s} \times \mathbf{L} / \mathbf{m o l}^{\mathbf{2}}\right)$ & Interception $\mathbf{( s / m o l})$ & Correlation coefficient & $\mathbf{K}_{\mathbf{i}}(\mathbf{m m o l} / \mathbf{L})$ \\
\hline 1 & $4.49 \times 10^{13}$ & $8.23 \times 10^{9}$ & 0.978 & 0.183 \\
0.5 & $5.75 \times 10^{13}$ & $9.43 \times 10^{9}$ & 0.976 & 0.164 \\
0.2 & $9.64 \times 10^{13}$ & $1.64 \times 10^{10}$ & 0.981 & 0.170 \\
0.1 & $2.38 \times 10^{13}$ & $4.41 \times 10^{10}$ & 0.966 & 0.185 \\
\hline
\end{tabular}

Table 2. Search on inhibitory mechanism using human BChE.

\begin{tabular}{ccccc}
\hline Substrate $(\mathbf{m m o l} / \mathbf{L})$ & Slope $\left(\mathbf{s} \times \mathbf{L} / \mathbf{m o l}^{\mathbf{2}}\right)$ & Interception $(\mathbf{s} / \mathbf{m o l})$ & Correlation coefficient & $\mathbf{K}_{\mathbf{i}}(\mathbf{m o l} / \mathbf{L})$ \\
\hline 5 & $2.76 \times 10^{8}$ & $6.60 \times 10^{9}$ & 0.277 & 24.0 \\
1 & $8.75 \times 10^{8}$ & $5.80 \times 10^{9}$ & 0.609 & 6.64 \\
0.2 & $4.62 \times 10^{8}$ & $5.07 \times 10^{9}$ & 0.400 & 11.0 \\
\hline
\end{tabular}

As seen in the experimental data, caffeine is a selective inhibitor of $\mathrm{AChE}$ and not $\mathrm{BChE}$. The fact that caffeine can inhibit AChE can be assumed from some papers [29-31]. The exact mechanism of the inhibition and the detailed comparison of $\mathrm{AChE}$ and $\mathrm{BChE}$, however, was not done. Though inhibition of $\mathrm{BChE}$ can be found, the inhibition constant is too high to be reached in the body. AChE activity can be affected more easily. It is noteworthy that caffeine is not a highly potent inhibitor of AChE. As seen from the quoted work about tacrine and donepezil, caffeine is approximately a 1000-times weaker inhibitor of AChE than tacrine and a 14,000-times weaker inhibitor than donepezil. On the other hand, caffeine is much less toxic than the mentioned drugs, and it is easier to give a higher dose to the body. 
The toxic effect of caffeine is assumed when plasmatic concentration reaches $25 \mathrm{mg} / \mathrm{L}$ (i.e., $129 \mu \mathrm{mol} / \mathrm{L}$ ), and intoxication with caffeine reaching a plasmatic level $85 \mathrm{mg} / \mathrm{L}(438 \mu \mathrm{mol} / \mathrm{L})$ is known $[32,33]$. The ability of caffeine to inhibit AChE was not known at the time of the mentioned case report. However, we can infer that a cholinergic crisis would take place in the intoxicated human, as the reached plasmatic concentration was above the inhibition constant for human AChE. Intake of caffeine in the form of chocolate, coffee, energy drinks or tea probably does not cause significant biological effects based on AChE inhibition. As proved in a study, an amount of caffeine of $100 \mathrm{mg}$ corresponding to one coffee results in a peak concentration of caffeine in plasma of approximately $2.0 \mathrm{mg} / \mathrm{L}$ $(10.3 \mu \mathrm{mol} / \mathrm{L})$ for men and $3.6 \mathrm{mg} / \mathrm{L}(18.5 \mu \mathrm{mol} / \mathrm{L})$ for women [34]. The quoted plasma concentration is 17-times under the $K_{i}$ in the case of men and 9.5-times under the $K_{i}$ for women. We can estimate that blood AChE is not significantly inhibited when people take one coffee. However, the combination of coffee and energy drink or caffeine tablets can easily reach plasmatic caffeine concentration when the AChE is inhibited.

Figure 3. The internal cavity of human $\mathrm{AChE}$ is visualized with the predicted binding orientation of caffeine, which is colored by red; the docked orientation of donepezil is colored by violet. Trp86 creating a stacking interaction is situated below the docked orientation of caffeine. Furthermore, there are other important amino acids having an interaction with caffeine (Ser125, Tyr133 and Tyr337). Additionally, His447 creates part of the active site for AChE.

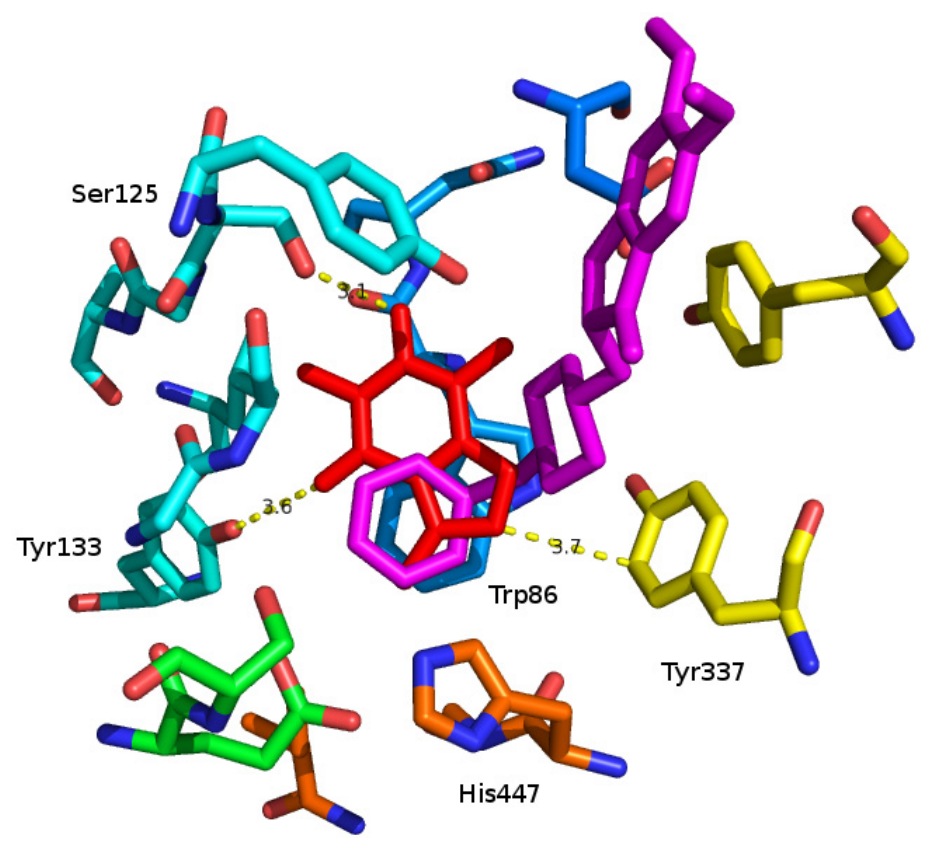

There was a proven lower incidence of Alzheimer disease in individuals taking coffee regularly [35,36]. This phenomenon is not commonly understood, despite efforts to find key macromolecules in the caffeine pathway [37]. Though some theories were established, none is confirmed on a molecular model. We infer that the inhibition of $\mathrm{AChE}$ can be responsible for the effect.

Non-competitive inhibitors blocking anionic sites of AChE are known to be able to improve cognitive functions during Alzheimer disease [5,18,38], and caffeine would act just as the 
non-competitive inhibitor. Besides the improving cognitive functions, there are hypotheses that the blocking of the peripheral anionic site of $\mathrm{AChE}$ could slow down deposition of amyloid plaques [4,5].

The fact that caffeine acts as a selective inhibitor is quite interesting. There is a continuous effort to introduce selective inhibitors in order to ameliorate side effects of drugs [39,40]. Since the etiology of Alzheimer disease is not revealed and many starting mechanisms, including oxidative stress, are currently considered [41-43], the effect of caffeine in clinical studies can be helpful. The findings given in clinical studies [35,36] can be attributed to inhibition of AChE rather than BChE. The second enzyme probably plays another role than AChE in Alzheimer disease development, and both enzymes are suspicious of being involved in the disease's development [44]. More work on the issue is needed prior to giving a serious explanation.

\section{Experimental Section}

\subsection{Cholinesterases Activity Assay}

Recombinant human $\mathrm{BChE}$ and recombinant human $\mathrm{AChE}$ were purchased from Sigma-Aldrich (Saint Louis, Missouri, USA). Both enzymes were received as a powder. The BChE had specific activity $\geq 500 \mu \mathrm{mol} / \mathrm{min} / \mathrm{mg}$ of protein and $\mathrm{AChE} \geq 1500 \mu \mathrm{mol} / \mathrm{min} / \mathrm{mg}$. Caffeine, tacrine and donepezil were purchased as analytical standards from Sigma-Aldrich. The other reagents were in a standard purity, and they were received from Sigma-Aldrich, as well.

Cholinesterases inhibition by the tested compounds was assayed using Ellman's method based on 5,5'-dithiobis-(2-nitrobenzoic) acid as chromogen and, butyrylthiocholine chloride (for BChE) and acetylthiocholine chloride (for AChE) as substrates. The principle and protocol for the assay was published in the quoted papers [45-47]. In the assay, standard PS disposable cuvettes were used. The cuvette was gradually filled with $0.4 \mathrm{~mL}$ of 5,5'-dithiobis-(2-nitrobenzoic) acid $0.4 \mathrm{mg} / \mathrm{mL}, 100 \mu \mathrm{L}$ of either $\mathrm{BChE}$ or AChE solution $\left(1 \times 10^{-9} \mathrm{~kat}\right.$ for $1 \mathrm{mmol} / \mathrm{L}$ substrate and standard ambient temperature and pressure (SATP) conditions) in phosphate buffered saline (PBS; composition $137 \mathrm{mmol} / \mathrm{L} \mathrm{NaCl}$, $2.7 \mathrm{mmol} / \mathrm{L} \mathrm{KCl}, 10 \mathrm{mmol} / \mathrm{L} \mathrm{Na}_{2} \mathrm{HPO}_{4}, 0.24 \mathrm{mmol} / \mathrm{L} \mathrm{KH} \mathrm{KHO}_{4}, \mathrm{pH} \mathrm{7.4),} 100 \mu \mathrm{L}$ of the tested compound solution in PBS and $300 \mu \mathrm{L}$ of PBS. The reaction was started by addition of butyrylthiocholine or acetylthiocholine chloride $(100 \mu \mathrm{L})$. Five minutes after substrate injection to the cuvette, absorbance was measured at $412 \mathrm{~nm}$. Enzyme activity was calculated using the extinction coefficient, $\varepsilon=14,150 \mathrm{~L} \times \mathrm{mol}^{-1} \times \mathrm{cm}^{-1}$. The coefficient was taken from the literature describing an experiment where the same assay conditions were used [48].

\subsection{Molecular Modeling}

The first polypeptide chain from the crystal structure of human AChE with donepezil was taken for modeling (pdb code 4EY7) [28]. The water and other molecules were removed, and the molecular program, Sirius (version 1.2, Supercomputer Center, San Diego, CA, USA), was used for preparation of the complex AChE inhibitors. Further structures were modified using the AutoDockTools scripts in order to be docked by AutoDock Vina 1.1.2 [49] with default parameters, where the grid center was situated on the inhibitor, in compliance with the crystal structure, and the grid size was equal to 
$27 \times 18 \times 23 \AA$. The orientation with the lowest free energy of binding was only considered according to the Vina score. The results were visualized with the help of the Pymol software [50].

\subsection{Statistical Processing of Experimental Data}

The experimental data were processed in compliance with Dixon's method [51,52]. The data were plotted by two ways: as a reciprocal value of velocity against inhibitor concentration and as a substrate concentration divided by reaction velocity against inhibitor concentration, as described by Cornish-Bowden [52]. The inhibition constants, $\mathrm{K}_{\mathrm{i}}$, were calculated from the plots. Non-competitive standard inhibitors were assayed for their $\mathrm{IC}_{50}$. If necessary, the $\mathrm{K}_{\mathrm{i}}$ value can be derived from the $\mathrm{IC}_{50}[53,54]$.

\section{Conclusions}

Caffeine is a simply available drug that has been known for a long time and by many cultures. Despite a lot of work on the identification of caffeine's effect in the body, some pathways remain undiscovered. In the present work, we proved that caffeine can act as a non-competitive inhibitor of AChE in the body. This finding can be expected in some of the clinically proven effects with no known molecular mechanism. We can emphasize that caffeine can be considered as a potential lead structure in drug design.

\section{Acknowledgments}

The Ministry of Education, Youth and Sports (Czech Republic) is gratefully acknowledged for "A long-term organization development plan 1011". The European Regional Development Fund and the state budget of the Czech Republic are acknowledged for project RECAMO, CZ.1.05/2.1.00/03.0101. The funder had no role in the study design, data collection and analysis or the decision to publish or to prepare the manuscript.

\section{Conflict of Interest}

The authors declare no conflict of interest.

\section{References}

1. Metherate, R. Functional connectivity and cholinergic modulation in auditory cortex. Neurosci. Biobehav. Rev. 2011, 35, 2058-2063.

2. Wessler, I.; Kirkpatrick, C.J. Acetylcholine beyond neurons: The non-neuronal cholinergic system in humans. Br. J. Pharmacol. 2008, 154, 1558-1571.

3. Pohanka, M. Alpha7 nicotinic acetylcholine receptor is a target in pharmacology and toxicology. Int. J. Mol. Sci. 2012, 13, 2219-2238.

4. Pohanka, M. Cholinesterases, a target of pharmacology and toxicology. Biomed. Pap. 2011, 155, 219-229.

5. Pohanka, M. Acetylcholinesterase inhibitors: A patent review (2008-present). Expert Opin. Ther. Pat. 2012, 22, 871-886. 
6. Jokanovic, M. Medical treatment of acute poisoning with organophosphorus and carbamate pesticides. Toxicol. Lett. 2009, 190, 107-115.

7. Marrs, T.C. Organophosphate poisoning. Pharmacol. Ther. 1993, 58, 51-66.

8. Pohanka, M. Alzheimer's disease and related neurodegenerative disorders: Implication and counteracting of melatonin. J. Appl. Biomed. 2011, 9, 185-196.

9. Holzgrabe, U.; Kapkova, P.; Alptuzun, V.; Scheiber, J.; Kugelmann, E. Targeting acetylcholinesterase to treat neurodegeneration. Expert Opin. Ther. Targets 2007, 11, 161-179.

10. Krall, W.J.; Sramek, J.J.; Cutler, N.R. Cholinesterase inhibitors: A therapeutic strategy for alzheimer disease. Ann. Pharmacother. 1999, 33, 441-450.

11. Bhat, K.G.; Singhal, V.; Borker, A.S. Successful treatment of vincristine induced ptosis and polyneuropathy with pyridoxine and pyridostigmine in a child with acute lymphoblastic leukemia. Indian J. Med. Paediatr. Oncol. 2012, 33, 185-187.

12. Yu, Q.S.; Holloway, H.W.; Luo, W.; Lahiri, D.K.; Brossi, A.; Greig, N.H. Long-acting anticholinesterases for myasthenia gravis: Synthesis and activities of quaternary phenylcarbamates of neostigmine, pyridostigmine and physostigmine. Bioorg. Med. Chem. 2010, 18, 4687-4693.

13. Iwasaki, T.; Yoneda, M.; Nakajima, A.; Terauchi, Y. Serum butyrylcholinesterase is strongly associated with adiposity, the serum lipid profile and insulin resistance. Intern. Med. 2007, 46, $1633-1639$.

14. Ostergaard, D.; Viby-Moogensen, J.; Hanel, H.K.; Skovgaard, L.T. Half-life of plasma cholinesterase. Acta Anaesthesiol. Scand. 1988, 32, 266-269.

15. Guilbeau, J.R. Health risks of energy drinks: What nurses and consumers need to know. Nurs. Women's Health 2012, 16, 423-428.

16. Sepkowitz, K.A. Energy drinks and caffeine-related adverse effects. JAMA 2013, 309, 243-244.

17. Potenza, R.L.; Armida, M.; Rerrante, A.; Pezzola, A.; Matteucci, A.; Puopolo, M.; Popoli, P. Effects of chronic caffeine intake in a mouse model of amyotrophic lateral sclerosis. J. Neurosci. Res. 2013, 91, 585-592.

18. Szadujkis-Szadurska, K.; Grzesk, G.; Szadujkis-Szadurski, L.; Gajdus, M.; Matusiak, G. Role of acetylcholine and calcium ions in three vascular contraction models: Angiotensin II, phenylephrine and caffeine. Exp. Ther. Med. 2012, 4, 329-333.

19. Glatter, K.A.; Myers, R.; Chiamvimonvat, N. Recommendations regarding dietary intake and caffeine and alcohol consumption in patients with cardiac arrhythmias: What do you tell your patients to do or not to do? Curr. Threat. Opt. Cardiovasc. Med. 2012, 14, 529-535.

20. Cummings, K.J.; Commons, K.G.; Trachtenberg, F.L.; Li, A.; Kinney, H.C.; Nattie, E.E. Caffeine improves the ability of serotonin-deficient $\left(\right.$ pet- $1^{-/}$) mice to survive episodic asphyxia. Pediatr. Res. 2013, 73, 38-45.

21. Golembiowska, K.; Dziubina, A. The effect of adenosine a(2a) receptor antagonists on hydroxyl radical, dopamine, and glutamate in the striatum of rats with altered function of vmat2. Neurotox. Res. 2012, 22, 150-157.

22. Shin, H.J.; Ryu, J.H.; Kim, S.T.; Zuo, Z.; Do, S.H. Caffeine-induced inhibition of the activity of glutamate transporter type 3 expressed in xenopus oocytes. Toxicol. Lett. 2013, 217, 143-148.

23. Daly, J.W. Caffeine analogs: Biomedical impact. Cell. Mol. Life Sci. 2007, 64, 2153-2169.

24. Ribeiro, J.A.; Sebastiao, A.M. Caffeine and adenosine. J. Alzheimers Dis. 2010, 20, S3-S15. 
25. Acquas, E.; Tanda, G.; DiChiara, G. Differential effects of caffeine on dopamine and acetylcholine transmission in brain areas of drug-naive and caffeine-pretreated rats. Neuropsychopharmacology 2002, 27, 182-193.

26. Tomaszewski, M.; Olchowik, G.; Tomaszewska, M.; Burdan, F. Use of X-ray microprobe to diagnose bone tissue demineralization after caffeine administration. Folia Histochem. Cytobiol. 2012, 50, 436-443.

27. Bai, D.L.; Tang, X.C.; He, X.C. Huperzine a, a potential therapeutic agent for treatment of alzheimer's disease. Curr. Med. Chem. 2000, 7, 355-374.

28. Cheung, J.; Rudolph, M.J.; Burshteyn, F.; Cassidy, M.S.; Gary, E.N.; Love, J.; Franklin, M.C.; Height, J.J. Structures of human acetylcholinesterase in complex with pharmacologically important ligands. J. Med. Chem. 2012, 55, 10282-10286.

29. Okello, E.J.; Leylabi, R.; McDougall, G.J. Inhibition of acetylcholinesterase by green and white tea and their simulated intestinal metabolites. Food Funct. 2012, 3, 651-661.

30. Karadsheh, N.; Kussie, P.; Linthicum, D.C. Inhibition of acetylcholinesterase by caffeine, anabasine, methyl pyrrolidine and their derivatives. Toxicol. Lett. 1991, 55, 332-342.

31. Stoytcheva, M.; Zlatev, R.; Velkova, Z.; Valdez, B.; Ovalle, M. Electrochemical study on the kinetic behavior of the immobilized acetylcholinesterase. ECS Trans. 2009, 20, 175-184.

32. Vukcevic, N.P.; Babic, G.; Segrt, Z.; Ercegovic, G.V.; Jankovic, S.; Acimovic, L. Severe acute caffeine poisoning due to intradermal injections: Mesotherapy hazard. Vojnosanit. Pregl. 2012, 69, 707-713.

33. Pohanka, M. Antioxidants countermeasures against sulfur mustard. Mini Rev. Med. Chem. 2012, $12,742-748$.

34. Yubero-Lahoz, S.; Pardo, R.; Farre, M.; Mathuna, B.O.; Torrens, M.; Mustata, C.; Perez-Mana, C.; Langohr, K.; Carbo, M.L.; de la Torre, R. Changes in cypla2 activity in humans after 3,4-methylenedioxymethamphetamine (mdma, ecstasy) administration using caffeine as a probe drug. Drug Metab. Pharmacokineti. 2012, 27, 605-613.

35. Chu, Y.F.; Chang, W.H.; Black, R.M.; Liu, J.R.; Sompol, P.; Chen, Y.M.; Wei, H.L.; Zhao, Q.Y.; Cheng, I.H. Crude caffeine reduces memory impairment and amyloid beta(1-42) levels in an alzheimer's mouse model. Food Chem. 2012, 135, 2095-2102.

36. Vila-Luna, S.; Cabrera-Isidoro, S.; Vila-Luna, L.; Juarez-Diaz, I.; Bata-Garcia, J.L.; Alvarez-Cervera, F.J.; Zapata-Vazquez, R.E.; Arankowsky-Sandoval, G.; Heredia-Lopez, F.; Flores, G.; et al. Chronic caffeine consumption prevents cognitive decline from young to middle age in rats, and is associated with increased length, branching, and spine density of basal dendrities in cal hippocampal neurons. Neuroscience 2012, 202, 384-395.

37. Oboh, G.; Agunloye, O.M.; Akinyemi, A.J.; Ademiluyi, A.O.; Adefegha, S.A. Comparative study on the inhibitory effect of caffeic and chlorogenic acids on key enzymes linked to alzheimer's disease and some pro-oxidant induced oxidative stress in rats' brain - In vitro. Neurochem. Res. 2013, 38, 413-419.

38. Hu, Y.Q.; Zhang, J.; Chandrashankra, O.; Ip, F.C.F.; Ip, N.Y. Design, synthesis and evaluation of novel heterodimers of donepezil and huperzine fragments as acetylcholinesterase inhibitors. Bioorgan. Med. Chem. 2013, 21, 676-683.

39. Karlsson, D.; Fallarero, A.; Brunhofer, G.; Mayer, C.; Prakash, O.; Mohan, C.G.; Vuorela, P.; Erker, T. The exploration of thienothiazines as selective butyrylcholinesterase inhibitors. Eur. J. Pharm. Sci. 2012, 47, 190-205. 
40. Catto, M.; Pisani, L.; Leonetti, F.; Nicolotti, O.; Pesce, P.; Stefanachi, A.; Cellamare, S.; Carotti, A. Design, synthesis and biological evaluation of coumarin alkylamines as potent and selective dual binding site inhibitors of acetylcholinesterase. Bioorg. Med. Chem. 2013, 21, 146-152.

41. Pohanka, M. Role of oxidative stress in infectious diseases. A review. Folia Microbiol. 2013, doi:10.1007/s12223-013-0239-5.

42. Sanchez-Lopez, F.; Tasset, I.; Aguera, E.; Feijoo, M.; Fernandez-Bolanos, R.; Sanchez, F.M.; Ruiz, M.C.; Cruz, A.H.; Gascon, F.; Tunez, I. Oxidative stress and inflammation biomarkers in the blood of patients with huntington's disease. Neurol. Res. 2012, 34, 721-724.

43. Ramalingam, M.; Kim, S.J. Reactive oxygen/nitrogen species and their functional correlations in neurodegenerative diseases. J. Neural. Transm. 2012, 119, 891-910.

44. Holmes, C.; Ballard, C.; Lehmann, D.; Smith, A.D.; Beaumont, H.; Day, I.N.; Khan, M.N.; Lovestone, S.; McCulley, M.; Morris, C.M.; et al. Rate of progression of cognitive decline in alzheimer's disease: Effect of butyrylcholinesterase K gene variation. J. Neurol. Neurosurg. Psychiatr. 2005, 76, 640-643.

45. Pohanka, M. Acetylcholinesterase based dipsticks with indoxylacetate as a substrate for assay of organophosphates and carbamates. Anal. Lett. 2012, 45, 367-374.

46. Pohanka, M. Spectrophotomeric assay of aflatoxin b1 using acetylcholinesterase immobilized on standard microplates. Anal. Lett. 2013, doi:10.1080/00032719.2012.757703.

47. Pohanka, M. Cholinesterases in biorecognition and biosensor construction, a review. Anal. Lett. 2013, doi:10.1080/00032719.2013.780240.

48. Eyer, P.; Worek, F.; Kiderlen, D.; Sinko, G.; Stuglin, A.; Simeon-Rudolf, V.; Reiner, E. Molar absorption coefficients for the reduced ellman reagent: Reassessment. Anal. Biochem. 2003, 312, 224-227.

49. Trott, O.; Olson, A.J. Software news and update autodock vina: Improving the speed and accuracy of docking with a new scoring function, efficient optimization, and multithreading. J. Comput. Chem. 2010, 31, 455-461.

50. Seeliger, D.; de Groot, B.L. Ligand docking and binding site analysis with pymol and autodock/vina. J. Comput. Aid. Mol. Des. 2010, 24, 417-422.

51. Dixon, M. The determination of enzyme inhibitor constants. Biochem. J. 1953, 55, 170-171.

52. Cornish-Bowden, A. A simple graphical method for determinating the inhibition constants of mixed, uncompetitive and non-competitive inhibitors. Biochem. J. 1973, 137, 143-144.

53. Cortes, A.; Cascante, M.; Cardenas, M.L.; Cornish-Bowden, A. Relationships between inhibition constants, inhibitor concentrations for $50 \%$ inhibition and types of inhibition: New ways of analysing data. Biochem. J. 2001, 357, 263-268.

54. Cer, R.Z.; Mudunuri, U.; Stephens, R.; Lebeda, F.J. Ic50-to-ki: A web-based tool for converting ic50 to ki values for inhibitors of enzyme activity and ligand binding. Nucleic Acids Res. 2009, 37, W441-W445.

(C) 2013 by the authors; licensee MDPI, Basel, Switzerland. This article is an open access article distributed under the terms and conditions of the Creative Commons Attribution license (http://creativecommons.org/licenses/by/3.0/). 